\title{
Engelsiz Kent: Görme Engelli Bireylerin Kentlerde Yaşadıkları Problemler
}

\author{
H. İrem Özteke Kozan \\ N. Erbakan Üniversitesi
}

\author{
Hasan Bozgeyikli \\ Erciyes Üniversitesi
}

\author{
Şahin Kesici \\ N. Erbakan Üniversitesi
}

\section{Öz}

Bu araştırmanin amacı, kentlerde yaşayan görme engelli bireylerin çevresel anlamda yaşadıkları problemlerin ortaya konulmasıdır. Bu amaçla, kentlerde çeşitli alanlarda problemler yaşayan görme engelli bireyler bu araştırmanın çalışma grubunu oluşturmaktadir. Nitel araştırma yönteminin kullanıldığı araştırmaya çeşitli düzeylerde görme engeli bulunan toplam on dört birey katılmıştır. Araştırmanın çalı̧ma grubunun oluşturulmasında kartopu örnekleme yöntemi kullanılmıştır. Verilerin toplanmasında önceden hazırlanan geçerliği ve güvenirlĭgi sağlanan yarı yapllandırılmış görüşme formundan yararlanılmıştır. Verilerin analizinde ise betimsel ve içerik analizi kullanılmıştır. Araştırma temalarmm belirlenmesinde betimsel analiz yöntemi kullanilmış ve beş tema oluşturulmuştur. Bu temalar, toplu ulaşım, park ve spor alanları, ortak kullanım alanları, resmi daireler ve hastaneler şeklinde oluşturulmuştur. Her temaya ait kategoriler ise içerik analizi yöntemi kullanılarak oluşturulmuştur. Araştırmadan elde edilen sonuçlara göre, görme engelli bireylerin toplu ulaşımda en çok yaşadikları problemler otobüslerde ve duraklardaki sesli sistemin olmamasıdır. Görme engelli bireylerin park ve spor alanlarında en çok yaşadıkları problemler sarı çizgiler, rampa ve tümsekler ile güvenliktir. Görme engelli bireylerin ortak kullanım alanlarında en sik yaşadıkları problemler temizlik problemi iken resmi dairelerde sesli ATM ve imza konusunda sıkıntı çekmektedirler. Hastanelerde ise bağımsız hareket, binaların fiziksel imkanları, kalabalık ve diğer insanların tutumları konusunda sıklkla problem yaşarken, en çok hastanelerde kendilerine görevli yardımı almak istemektedirler. Elde edilen sonuçlar ilgili alan yazın doğrultusunda tartışlmış ve önerilere yer verilmiştir.

Anahtar Kelimeler: Görme engelli, kent yaşamı, engelsiz kent, çevresel problem, ulaşılabilirlik 


\title{
Unimpaired City: Problems of Visually Impaired People in City Life
}

\author{
H. İrem Özteke Kozan \\ N. Erbakan University
}

\author{
Hasan Bozgeyikli \\ Erciyes University
}

\author{
Şahin Kesici \\ N. Erbakan University
}

\begin{abstract}
Aim of current study is to reveal the environmental problems in cities via qualitative method. For that purpose, study group consists of visually impaired people have problems in towns. Fourteen visually impaired people participated into study. Moreover, snowball sampling was used in current study. In data collection, semi-structured interview form was used. Reliability and validity was provided before collecting data. In analyzing data, descriptive and content analysis was used, themes and categories were created. These themes were difficulties in public transportation, park and sports areas, common use areas, state offices and hospital. In accordance to these themes, categories were created via content analysis. Participants reported that they mostly have problems regarding to voice systems in buses and stops. They generally need to ask someone to learn the stop or bus name. In parks and sport areas they generally have problems related to yellow lines, ramps and security. In common use areas, they suffer from cleaning and in state offices they complain about ATM systems and signing the documents. For the last theme -hospitals- participants mostly have problems regarding others' attitudes, pyhsical structure of building and crowd. Their suggestions for hospital generally focus on providing an officer to help them during their hospital visit. Findings were discussed and suggestions were givens in line with results.
\end{abstract}

Keywords: Visually impaired, city life, unimpaired city, environmental problems, accessibility. 


\section{Giriş}

Endüstrileşme ile birlikte hızla büyüyen kentler, giderek plansız bir şekilde yapılanmaya başlamış ve bu da kentlerdeki bireylerin yaşamlarını giderek güç hale getirmiştir. Herhangi bir engel grubuna dâhil olmayan bireylerin bile yaşamları plansız ve çarpık kentleşme ile problemlere yol açarken, engelli bireylerin yaşamları plansız kentleşme ile giderek zorlaşmaktadır (Bekci, 2012). Mobilya, konut ya da çevre tasarımından kaynaklanan uygulamalar özellikle engelli bireylerin yaşam kalitesinin düşmesine yol açabilmektedir (Çınar, Arslan, Öztürk ve Bülbül, 2015, s.330). Engelli bireylerin de diğer bireylerden kendilerini farklı hissetmeden diğerleri ile eşit şekilde kentsel yaşamdan faydalanabilmesi önem taşımaktadır çünkü onların da kentsel yaşama katılma hakkı vardır (Şat ve Göver, 2017, s.527). Ülkemizde (Bekci, 2012; Çınar vd., 2015; Kaplan ve Öztürk, 2004; Uslu ve Shakouri, 2014) ve uluslararası alan yazındaki (Beverley, Bath ve Booth, 2004; Bromley, Matthews ve Thomas, 2007; Rimmer, Riley, Wang, Rauworth ve Jurkowski, 2004) araştırmalar incelendiğinde çeşitli engel grubuna sahip bireylerin kent yaşamında yaşadıkları problemler ele alınmıştır. Bu araştırmada da görme engelli bireylerin kent yaşamında özellikle ulaşım, park ve bahçeler, ortak kullanım alanları, resmi daireler ve hastanelerde yaşadıkları problemler ve çözüm önerileri kendi görüşleri doğrultusunda incelenmektedir. Her ne kadar kent yaşamının düzenlenmesinde çeşitli tasarı ve raporlar hazırlanmış ve yayınlanmış olsa da görme engellilere yönelik düzenlenen kent kurallarının uygulanabilirliği konusunda bazı sıkıntılar yaşanmaktadır. Bu anlamda bu araştırma özellikle görme engeline sahip bireylerin yaşadıkları problemleri ve çözüm önerilerini nitel araştırma yöntemi kullanılarak ele alması açısından alan yazında önemli bir yere sahiptir.

\section{Görme Engelli Bireyler ve Kentlerde Yaşadıkları Problemler}

Sağlık ve sosyal hizmetlerde eşitsizlik ve yetersizliklerin azaltılmasında bilgiye ulaşma en önemli anahtardır. Ancak bilgiye her zaman ulaşılamamakta ya da belli grup bireylerin ihtiyaçları karşılanamamaktadır. Bu gruplardan biri de görme engelli bireylerdir (Beverley, vd., 2004). Engelliler kent mekânlarını kullanırken ve kent içi yolculuklarında fiziksel, psikolojik ve ekonomik engellerle karşılaşabilmektedirler. Erişebilirlik ve hareketlilik gereksinimleri bağlamında engellilerin karşılaştı̆g fiziksel 
engeller diğer bireylerin karşılaştıklarından çok daha fazladır ve bu sorunun çözümü en önemli gereksinimlerden biri olmalıdır (Kaplan ve Ulvi, 2009, s. 1483). Tüm insanlar için kentlerin yaşanırlığg önemlidir ancak engelli bireyler için engelsiz ve ulaşılabilir kent çok daha büyük önem taşımaktadır (Çakır Sümer, 2015).

Diğer engel grupları içinde incelendiğinde, görme engellilerin hayatlarını diğerlerinden daha bağımsız bir şekilde yürütebilmeleri için daha fazla desteğe ihtiyaçları vardır (Aydın, 2012, s. 94). Görme kaybı kişinin çevresinde hareket etmesini, yeni çevreleri tanımasını ve kamu taşıtlarını kullanımını sınırlandırmaktadır. Görme engelli bireylerin sosyal yaşamlarında kendi günlük işlerini yapabilmeleri evden okula ya da markete vb. yerlere gidebilmeleri önemlidir. Özellikle trafikte gerekli temel becerileri bilmeleri de gereklidir. Çünkü bu durum engelli bireylerin toplum içinde bağımsız hareket etmesine yardımcı olacaktır (Çakmak, 2011, s. 95).

Görme engellilerin kent yaşamında en çok yaşadıkları problemler incelendiğinde bunlar trafikte, kaldırımlarda ya da kent mobilyalarında (Şat ve Göver, 2017) kendini göstermektedir. Kentler çoğunlukla taşıtların hızlı hareket etmesine imkân sağlarken özellikle toplu taşıma araçları da görme engelli bireylere büyük problemler yaşatmaktadır. Engellilere göre tasarlanmayan alt ve üst geçitler de engelli bireylerin toplum hayatına katılmalarına engel olmaktadır. Bunun yanı sıra kaldırım yükseklikleri, rampalar ve kaldırım üzerinde yer alan mobilyalar ile park eden araçlar da kaldırımlarda görme engellilere kent yaşamında birçok zorluk oluşturmaktadır (Şat ve Göver, 2017). Engelli bireyler kent içinde yaşadıkları problemler nedeniyle, ayrica kurumların ve binaların uygun yapılmaması sebebiyle de birçok zorlukla karşılaşmaktadır (Yılmaz ve Özservet, 2013). Eğitim perspektifinden bakıldığında ise, üniversite eğitimi almaya hak kazanmış görme engelli öğrencilerin diğer görme engellilere göre daha çeşitli bilgiye ihtiyaçları vardır. Özellikle kütüphaneler görme engelli öğrencilerin ihtiyaçlarına cevap verecek nitelikte düzenlenmelidir ve bu öğrencilerin de bilgi kaynağına erişimine imkan tanımalıdır (Aydın, 2012). Görme engelli öğrencilerin problemleri en aza indirgenmesinin öğrenme sürecine katkısı da tartışılmazdır (Pirgon ve Babacan, 2013).

Engellilere yönelik tasarım konusunda yaşanılan en büyük sıkıntılardan biri normal bireylerin engelli ihtiyaçları ile ilgili deneyim eksikliğidir. Örneğin bir otel odasının elektrik anahtarı yüksekliğinde yapılacak küçük bir değişiklik normal birey için pek bir şey ifade etmezken engelli 
birey için çok önemli olabilmektedir (Pehlivanoğlu, 2012). Her ne kadar kanun ve yönetmeliklerde engelli hakları ve kent yaşamı planlarının standart ölçüleri belirtilmiş olsa da özellikle uygulama alanında birçok problemler yaşanabilmektedir. Ayrıca bazı büyük şehirlerde bu uygulamaların bir kısmına yer verilmiş olsa da her kentte bu uygulamalar yürütülmemektedir. Özetle, bu araştırmanın amacı, görme engelli bireylerin kent yaşamında yaşadıkları problemleri nitel araştırma yöntemi ile ele alarak bu problemlere dikkat çekmek ve çözüm önerileri sunmaktır.

\section{Yöntem}

$\mathrm{Bu}$ araştırmada nitel araştırma yöntemlerinden biri olan olgu bilim kullanılmıştır. Olgu bilim yöntemi nitel araştırma, gözlem görüşme ve doküman analizi gibi nitel veri toplama yöntemlerinin kullanıldığı, algıların ve olayların doğal ortamda gerçekçi ve bütüncül bir biçimde ortaya konulmasına yönelik nitel bir sürecin izlendiği araştırmalardır (Yıldırım ve Şimşek, 2006).

\section{Çalışma Grubu}

$\mathrm{Bu}$ araştırmanın çalışma grubunu Konya, Elazı̆̆g, Eskişehir ve Mersin, Ankara gibi Türkiye'nin farklı illerinde yaşayan görme engelli bireyler oluşturmaktadır. Çalışma grubu farklı düzeylerde görme engeli bulunan 14 görme engelli bireylerden oluşmaktadır. Araştırmada kullanılan örnekleme yöntemi kartopu örneklemedir. Kartopu örnekleme, nitel araştırmalarda veri toplamada süreç ilerledikçe elde edilen isimlerin veya durumların tıpkı kartopu gibi büyüyerek devam ettiği bir örnekleme yöntemidir (Yıldırım ve Şimşek, 2006).

\section{Yarı Yapılandırılmış Görüşme Tekniği}

Araştırmada verilerin toplanmasında yarı yapılandırılmış görüşme tekniği kullanılmıştır. Görüşme formunun oluşturulduğu ilk aşamada öncelikle alan yazın taraması yapılarak görme engellilerin kent yaşamında sıklıkla karşılaştıkları sorunlar belirlenmeye çalışılmıştır. Buna bağlı olarak yarı yapılandırılmış görüşme formu oluşturulmuştur. Görüşme formunun geçerliğini sağlamak üzere form, Özel Eğitim ile Rehberlik ve Danışma alanında doktora derecesine sahip beş öğretim üyesi tarafından değerlendirilmiştir. Uzman görüşleri kapsamında form üzerinde gerekli düzenleme ve değişiklikler yapılmıştır. Daha sonra pilot 
uygulama yapılmıştır. Pilot uygulama da kent yaşamında problem yaşayan görme engelli bireylerle yürütülmüştür. Alınan geri bildirimler doğrultusunda görüşme formu son şeklini almıştır.

\section{Verilerin Toplanması}

Verilerin toplanmasında gönüllü katılım esas alınmıştır. Ayrıca katılımclara toplanan bilgilerin gizli kalacağı ve kimliklerinin gizli tutulacağ1 bilgisi verilmiştir. Veriler, görüşme formu aracılığ1 ile toplanmıştır. Görüşmeler yaklaşık 20-25 dakika civarında sürmüştür.

\section{Verilerin Analizi ve Yorumlanmas1}

Verilerin analiz edilmesinde betimsel analiz ve içerik analizi tekniğinden yararlanılmıştır. İçerik analizinde temel amaç, toplanan verileri açıklayabilecek kavramlara ve ilişkilere ulaşmaktır. Betimsel analizde özetlenen ve yorumlanan veriler içerik analizinde daha derin bir işleme tabi tutulur ve betimsel bir yaklaşımla fark edilemeyen kavram ve temalar bu analiz sonucu keşfedilebilir. Bu amaçla toplanan verilerin önce kavramsallaştırılması daha sonra da ortaya çıkan kavramlara göre mantıklı bir biçimde düzenlenmesi ve buna göre veriyi açıklayan temaların saptanması gerekmektedir (Yıldırım ve Şimşek, 2006). Katılımcıların görüşleri formlar aracılığı ile toplanarak verilerin analizi kısmında her bir katılımcı formu birden başlanarak kodlanmıştır. Görme engelli bireylerin kent yaşamında yaşadıkları problemler ve çözüm öneriler hem betimsel analiz hem de içerik analizi kullanılarak tema ve kategoriler şeklinde düzenlenmiştir. Tema ve kategorilere ilişkin örnek görüşlere ise bulgular kısmında yer verilmiştir.

\section{Bulgular}

Görme engelli bireylerin kentlerde yaşadıkları problemler ve çözüm önerilerine yönelik olarak elde edilen sonuçlar betimsel analiz yöntemi ile analiz edilerek beş tema oluşturulmuştur. Bu temalar, toplu ulaşım, park ve spor alanları, ortak kullanım alanları, resmi daireler ve hastaneler şeklinde oluşturulmuştur. Her temaya ait kategoriler ise içerik analizi yöntemi kullanılarak oluşturulmuş ve aşağıdaki tablolarda örnek görüşlerle birlikte yer almaktadır. Ayrıca katılımcılardan elde edilen görüşler her bir tema altında hem yaşanılan problemler hem de çözüm önerileri olmak üzere iki şekilde incelenmiştir. 


\section{Toplu Ulaşım teması}

Toplu ulaşım temasına ait yaşanılan sorunlar incelendiğinde otobüs ve duraklarda yaşanan sıkıntılar, yer bulma, sistemlerin çalışmaması ve bilinçlenme olmak üzere beş kategori oluşturulmuştur. Çözüm önerilerine yönelik olarak ise, sesli sistem, durakta sesli sistem, fosforlu işaret, bilinçlendirme, akıllı telefon uygulaması, şoför eğitimi ve bilgi kartı olmak üzere kategoriler belirlenmiştir.

Tablo 1. Toplu ulaşım temasına ait kategoriler ve örnek görüşler

\begin{tabular}{|c|c|}
\hline \multicolumn{2}{|r|}{ Yaşanılan problemler } \\
\hline Kategori & Örnek görüş \\
\hline $\begin{array}{l}\text { Otobüs } \\
\text { (7 katılımcı) }\end{array}$ & $\begin{array}{l}\text { “Otobüslerde hangi durağa geldiğimizi bilememek bizim için çok büyük } \\
\text { bir sıkıntı. Bindiğimizde şoförden rica ediyoruz. Onlar da bazen unutu- } \\
\text { yorlar durağı kaçırıyoruz.” (K1) } \\
\text { "Otobüs durağa yaklaşırken hangi durağa geldiğimizi bilmiyoruz. } \\
\text { Sürekli ya yanımızda biri oluyor ya da şoföre sormak zorunda kalıyo- } \\
\text { rum." (K4) }\end{array}$ \\
\hline $\begin{array}{l}\text { Durak } \\
(5 \text { katılımcı) }\end{array}$ & $\begin{array}{l}\text { "Bazı duraklarda akıllı ekranlar var ancak bir duraktan bir sürü otobüs } \\
\text { geçiyor. O duraktan hangi otobüs geçtiğini bilemiyoruz. Bazı büyük } \\
\text { şehirlerde var diye duyuyorum." (k5) }\end{array}$ \\
\hline $\begin{array}{l}\text { Yer bulma } \\
\text { (3 katılımc1) }\end{array}$ & $\begin{array}{l}\text { "Yer bulma konusunda çok sıkıntı yaşıyorum. Engellilere yer verilmi- } \\
\text { yor." (K6) } \\
\text { "Bizler için ayrılan yerlere başka insanlar oturuyor. Yer bulamıyorum." } \\
\text { (E6) }\end{array}$ \\
\hline $\begin{array}{l}\text { Sistemlerin } \\
\text { çalışmaması } \\
(2 \text { katılımcı) } \\
\end{array}$ & $\begin{array}{l}\text { "Otobüslerde sesli sistem var ama hep cihaz bozuk. Şoförler rahatsız } \\
\text { olduğu için kapatıyor da olabilir. Sistemlerin işlevselliği yok." (E5) }\end{array}$ \\
\hline $\begin{array}{l}\text { Bilinçlendirme } \\
\text { (1 katılımcı) }\end{array}$ & $\begin{array}{l}\text { "Otobüslerde sistem çalışsa bile diğerleri sıkıntı yapıyor. Bu yüzden } \\
\text { şoför kapatıoor." (E5) }\end{array}$ \\
\hline Çözüm önerileri & \\
\hline Kategori & Örnek görüş̧ \\
\hline $\begin{array}{l}\text { Sesli sistem } \\
\text { (Otobüslerde) } \\
\text { (11 katılımcı) }\end{array}$ & $\begin{array}{l}\text { "Otobüslerde sesli sistem olması gerekir. Bazı şehirlerde var ancak her } \\
\text { yerde yok. Hangi durağa geldiğimizi söyleyen sesli sistem olması gere- } \\
\text { kir." (K1) } \\
\text { “Otobüs duraklarına geldiğimizi söyleyen sesli anons sistemleri kurula- } \\
\text { bilir. Bu çok gerekli bizim için." (E2) }\end{array}$ \\
\hline $\begin{array}{l}\text { Duraklarda sesli } \\
\text { sistem } \\
(5 \text { katılımcı) }\end{array}$ & $\begin{array}{l}\text { "Bazı duraklarda akıllı durak sistemleri var. Bu durakların yanına bar- } \\
\text { kodlar konulabilir. Bu şekilde otobüsün gelmesine kaç dakika kaldığını } \\
\text { öğrenebiliriz." (K8) }\end{array}$ \\
\hline $\begin{array}{l}\text { Fosforlu işaret- } \\
\text { ler } \\
(1 \text { katılımcı) }\end{array}$ & $\begin{array}{l}\text { "Az görenler için otobüs numarasını yazısını görebileceği fosforlu ve } \\
\text { büyük puntolu yazı işaretleri kullanılabilir." (K2) }\end{array}$ \\
\hline $\begin{array}{l}\text { Bilinçlendirme } \\
\text { (4 katılımcı) }\end{array}$ & $\begin{array}{l}\text { "Halkın bilinçlenmesi gerekiyor. Yardımcı olup yer vermiyorlar. Olanlar } \\
\text { var elbette. Ama insanların engelli bireylere yönelik tutumları konusun- } \\
\text { da mutlaka bilinçlenmeleri gerekir." (E2) }\end{array}$ \\
\hline Akılli telefon & "Akıllı telefon uygulamaları güzel olur. Özel bir sistem olabilir. Otobüs \\
\hline
\end{tabular}




\begin{tabular}{|c|c|}
\hline $\begin{array}{l}\text { uygulaması } \\
\text { (1 katılımcı) } \\
\end{array}$ & $\begin{array}{l}\text { geliyor. Şu kadar dakika kaldı gibi söyleyebilir. Durak kalabalıksa biri } \\
\text { söyleyebilir ama her zaman durakta birilerini bulamayabilirsiniz." (E3) }\end{array}$ \\
\hline $\begin{array}{l}\text { Şoför eğitimi } \\
\text { (1 katılımcı) }\end{array}$ & $\begin{array}{l}\text { "Şoförlere belli eğitimler verilerek durağa geldiğinde engelli birey gör- } \\
\text { dügünde durup seslenebilir. Bana hem daha insancıl hem daha basit ve } \\
\text { ucuz geliyor. Bazı ülkelerde bunu yapıyorlar. Bu bana çok makul gel- } \\
\text { mişti." (E3) }\end{array}$ \\
\hline $\begin{array}{l}\text { Bilgi kartları } \\
\text { (1 katılımcı) }\end{array}$ & $\begin{array}{l}\text { "Bazı ülkelerde taksilerin kapılarının iç kısımlarında bilgi kartları var } \\
\text { Brail alfabesi ile yazılmış. İstanbul'da bu var. Tüm kentlerde de yaygın- } \\
\text { laştırılabilir." (E3) }\end{array}$ \\
\hline
\end{tabular}

\section{Park ve spor alanları teması}

Park ve spor alanları temasında yaşanılan problemlere yönelik olarak, sarı çizgi, güvenlik, kaldırım, yapıştırılmış sarı çizgiler, rampa/tümsek, şehir planı, yazıların büyüklügüu, spor mekânlarına erişim, uygulanabilir olmak üzere bazı kategoriler belirlenmiştir. Çözüm önerilerine yönelik olarak ise, sarı çizgi uygulamaları, işaret sistemi, bilinçlendirme, şehir planı, akıllı/dokunmatik harita, sesli spor aleti/levha şeklinde kategoriler oluşturulmuştur.

Tablo 2. Park ve spor alanları temasına ait kategoriler ve örnek görüşler

\begin{tabular}{|c|c|}
\hline \multicolumn{2}{|r|}{ Yaşanılan problemler } \\
\hline Kategori adı & Örnek görüş \\
\hline $\begin{array}{l}\text { Sarı çizgi } \\
(2 \text { katılımcı) }\end{array}$ & $\begin{array}{l}\text { "Sarı çizgiler çok yetersiz. Bir yere kadar takip edebiliyorsunuz. Sonrası } \\
\text { kalbinin götürdüğü yere git misali. Parklarda yok bile. Görme engelliy- } \\
\text { seniz gidemezsiniz bile tek başınıza." (K1) }\end{array}$ \\
\hline $\begin{array}{l}\text { Güvenlik } \\
\text { (2 katılımc1) }\end{array}$ & $\begin{array}{l}\text { "Bazı parklarda açık alanlar var. Biz yürürken bu çukur ve açık alanla- } \\
\text { ra düşebiliriz" (K2) }\end{array}$ \\
\hline $\begin{array}{l}\text { Kaldırım engelleri } \\
\text { (3 katılımcı) }\end{array}$ & $\begin{array}{l}\text { "Kaldırıma çok araba park ediyor. Esnaf masa, sandalye koyuyor. } \\
\text { Kaldırımlar zikzaklı. Labirent gibi. Direkten iki metre sonra ağaç var. } \\
\text { Normal insanlar bile yürürken zikzak çizmek zorunda kalıyor." (E2) }\end{array}$ \\
\hline $\begin{array}{l}\text { Yapıştırılmış sarı } \\
\text { çizgi } \\
(1 \text { katılımcı) }\end{array}$ & $\begin{array}{l}\text { "Sarı çizgiler yapıştırıldığı için bazen onlar kalkıyor kışın da zor oluyor } \\
\text { kayıyor." (K3) }\end{array}$ \\
\hline $\begin{array}{l}\text { Rampa/tümsek } \\
\text { (3 katılımc1) }\end{array}$ & $\begin{array}{l}\text { "Parklarda rampalar var ancak normal insanlar bile yürüyerek çıamı- } \\
\text { yor biz nasıl çıkalım?" (E1) }\end{array}$ \\
\hline $\begin{array}{l}\text { Şehir planı } \\
(1 \text { katılımc1) }\end{array}$ & $\begin{array}{l}\text { "Özellikle şehir planı ile ilgili düzenlemeler yapılmalı, çünkü her ne } \\
\text { kadar bazı standartlar olsa da şehir planları buna izin vermiyor" (E3) }\end{array}$ \\
\hline $\begin{array}{l}\text { Yazıların büyüklüğü } \\
\text { (1 katılımcı) }\end{array}$ & $\begin{array}{l}\text { "Ben az gördüğüm için yazıların puntosu bana küçük geliyor zaten az } \\
\text { gördüğüm için sıkıntı yaşıorum” (K7) }\end{array}$ \\
\hline $\begin{array}{l}\text { Spor mekânlarına } \\
\text { erişim } \\
\text { (1 katılımcı) }\end{array}$ & $\begin{array}{l}\text { "Mesela ben görme engelliyim ama yüzmeye gitmek istiyorum. Spor } \\
\text { salonuna gitmek istiyorum. Maalesef gerekli düzenlemeler olmadığ1 } \\
\text { için gidemiyorum." (K8) }\end{array}$ \\
\hline $\begin{array}{l}\text { Uygulanabilirlik } \\
\text { (1 katılımcı) }\end{array}$ & $\begin{array}{l}\text { "Bazı dükkanların önünden sarı çizgi geçiyor. Belediye de buna yaptı- } \\
\text { rım uyguluyor ceza keseceğim diyor. Ancak fayda etmiyor. Yine kaldı- } \\
\text { rımlara dükkanlar sandalye masa koyuyor. Yani işlevsellik uygulanabi- }\end{array}$ \\
\hline
\end{tabular}




\begin{tabular}{ll}
\hline & lirlik yok." (E5) \\
\hline Çözüm önerileri & \\
\hline Kategori & Örnek görüş \\
\hline $\begin{array}{l}\text { Sarı çizgi } \\
\text { (6 katılımcı) }\end{array}$ & "Parkların birçok yerine sarı çizgiler konulabilir" (K4) \\
\hline İşaret sistemi & "Mesela parklarda lavaboyu, mescidi gösteren işaretler konulabilir" \\
(2 katılımcı) & (K2) \\
\hline Bilinçlendirme & "Görme engelliler için bastonla yürüyüş yolunu herkes kullandığı için \\
(2 katılımcı) & insanlar bilinçlendirilmelidir." (E2) \\
\hline Şehir planı & "Her ne kadar görme engelliler içi bazı düzenlemeler kentlerde yapılsa \\
(2 katılımcı) & da şehir planlarında düzenlemelere gidilmelidir." (E3) \\
\hline $\begin{array}{l}\text { Akıllı/dokunmatik } \\
\text { harita }\end{array}$ & "Park ve bahçelerde dokunmatik ya da sesli harita olması lazım." (E3) \\
(1 katılımcı) & \\
\hline $\begin{array}{l}\text { Sesli spor ale- } \\
\text { ti/levha }\end{array}$ & "Spor aletleri seslendirilebilir. Sesli spor aletleri konulabilir. Böylece \\
(1 katılımcı) & parklarda bizler de spor yapabiliriz." (K8) \\
\hline
\end{tabular}

\section{Ortak kullanım alanları teması}

Ortak kullanım alanları temasında yaşanılan problemlere yönelik olarak duvarlar, temizlik, cinsiyet işareti ve yer göstergesi olarak bazı kategoriler belirlenmiş olmakla birlikte 7 katılımcı ortak kullanım alanlarında problem yaşamadığını belirtmiştir. Çözüm önerileri konusunda ise Brail alfabesi, fiziksel koşullar, temizlik ve navigasyon uygulaması olmak üzere kategoriler belirlenmiştir. 4 katılımcı ise çözüm önerisi noktası fikri olmadığını ifade etmiştir.

Tablo 3. Ortak kullanım alanları temasına ait kategoriler ve örnek görüşler

\begin{tabular}{|c|c|}
\hline \multicolumn{2}{|r|}{ Yaşanılan problemler } \\
\hline Kategori adi & Örnek görüş \\
\hline $\begin{array}{l}\text { Duvar } \\
\text { (1 katılımc1) }\end{array}$ & $\begin{array}{l}\text { "Örneğin fakültede birden duvar kesiliyor kolon duvarı kesiyor. Biz nor- } \\
\text { malde kapı sayarak yol bulabiliriz ama kolon kestiği için bu bize çok prob- } \\
\text { lem yaratıyor." (K3) }\end{array}$ \\
\hline $\begin{array}{l}\text { Temizlik } \\
\text { (3 katılımcı) }\end{array}$ & $\begin{array}{l}\text { "Tuvaletler çok pis. Çok görmüyoruz ama kirli oluyor. Görmediğimiz için } \\
\text { bilemiyoruz ama fark ediyoruz." (K6) }\end{array}$ \\
\hline $\begin{array}{l}\text { Cinsiyet işareti } \\
\text { (1 katılımcı) }\end{array}$ & $\begin{array}{l}\text { "Tuvaletlerin kapısında cinsiyetleri belirten işaretler olmadığı için çok sıkın- } \\
\text { tı yaşıyorum. Mutlaka yanımda biri oluyor ya da sormak zorunda kalıyo- } \\
\text { rum." (K5) }\end{array}$ \\
\hline $\begin{array}{l}\text { Yer göstergesi } \\
\text { (1 katılımcı) }\end{array}$ & $\begin{array}{l}\text { "Ortak kullanım alanlarında özellikle lavaboların nerede olduğunu gösteren } \\
\text { yer göstergeleri olmadığı için bilmediğimiz bir yerde bağımsız hareket } \\
\text { edemiyoruz. İlla ki birine sormak zorunda kalıyoruz." (E4) }\end{array}$ \\
\hline \multicolumn{2}{|l|}{ Çözüm önerileri } \\
\hline Kategori & Örnek görüş \\
\hline $\begin{array}{l}\text { Brail alfabesi } \\
\text { (4 katılımcı) }\end{array}$ & "Engelliler için Brail alfabesi olabilir." (E1) \\
\hline
\end{tabular}




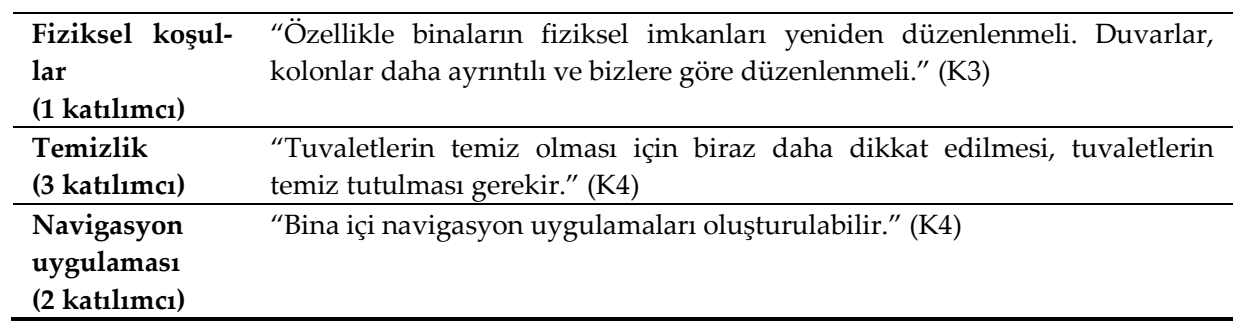

\section{Resmi Daireler Teması}

Resmi daireler temasında yaşanılan problemlere yönelik olarak ATM, sıra ve takibi, imza, şahitlik ve fiziksel koşullar gibi kategoriler belirlenmiştir. Katılımcıların görüşleri doğrultusunda ise çözüm önerilerine yönelik sesli sistem (ATM), bilinçlendirme, sesli imza, görevli yardımı, fişlerde kabartma, kılavuz izi olmak üzere bazı kategoriler ortaya çıkmıştir.

Tablo 4. Resmi Daireler temasına ait kategoriler ve örnek görüşler

\begin{tabular}{|c|c|}
\hline \multicolumn{2}{|r|}{ Yaşanılan problemler } \\
\hline Kategori adı & Örnek görüş \\
\hline $\begin{array}{l}\text { ATM } \\
\text { (4 katılımc1) }\end{array}$ & $\begin{array}{l}\text { "Birkaç ATM'de sesli sistem olsa da genellikle bulamıyorum. Kendi } \\
\text { başıma para çekemiyorum. İlla yanımda biri olması gerekiyor." (K1) }\end{array}$ \\
\hline $\begin{array}{l}\text { Sira takibi } \\
\text { (3 katılımcı) }\end{array}$ & $\begin{array}{l}\text { "Sira alamıyoruz. Alsak bile sirayı takip edemiyoruz. Bazı yerlerde var } \\
\text { bazı yerlerse buna uymuyor." (K2) }\end{array}$ \\
\hline $\begin{array}{l}\text { İmza } \\
\text { (4 katılımcı) }\end{array}$ & $\begin{array}{l}\text { "İmza ile alakalı sorunlar var. Yasal standartlar oturtuldu. Tabi ki bir } \\
10 \text { yıl öncesine göre böyle değil ama hala imza ile ilgili sorunlar yaşı- } \\
\text { yorum." (E1) } \\
\text { "Ben bir keresinde hesap açtırmak için gittim. Personel önüme bir } \\
\text { belge koydu. Adres, TC vs yazmamı istedi. İmza ile ilgili sıkıntılar } \\
\text { yaşıyorum." (K5) }\end{array}$ \\
\hline $\begin{array}{l}\text { Şahitlik } \\
\text { (2 katılımcı) }\end{array}$ & $\begin{array}{l}\text { "Şahitlik yapsın birileri istiyorlar. Noterde falan imza atarken şahit } \\
\text { bulun diyorlar. Bir keresinde noterde işim vardı birileri şahitlik yapsın } \\
\text { dediler. Kimse de şahit olmak istemez. Çok zorluk yaşamıştım." (K6) }\end{array}$ \\
\hline $\begin{array}{l}\text { Fiziksel koşullar } \\
\text { (2 katılımcı) }\end{array}$ & “Binaya girerken basamak sistemi sorun yaşatıyor." (K7) \\
\hline \multicolumn{2}{|l|}{ Çözüm önerileri } \\
\hline Kategori & Örnek Görüş \\
\hline $\begin{array}{l}\text { Sesli sistem } \\
(\text { ATM) } \\
(6 \text { katılımcı) }\end{array}$ & $\begin{array}{l}\text { "ATM'lerin hepsi istisnasız seslendirilmeli. Bazılarında var ama hep- } \\
\text { sinde yok. Bu yüzden bütün ATM'lere sesli sistem konulmalı. Böylece } \\
\text { işimizi bağımsız bir şekilde halledebiliriz." (K8) }\end{array}$ \\
\hline $\begin{array}{l}\text { Bilinçlendirme } \\
\text { (2 katılımcı) }\end{array}$ & $\begin{array}{l}\text { "Çalışanlar bilinçlendirilmeli. Bankada anlayışlı personele denk gelir- } \\
\text { sen yardımcı oluyor öncelik veriliyor. Değilse sıranı bekle deniliyor." } \\
\text { (E5) }\end{array}$ \\
\hline $\begin{array}{l}\text { Sesli imza } \\
\text { (1 katılımcı) }\end{array}$ & $\begin{array}{l}\text { "İmza da problem yaşadığım için sesli imza sistemi kullanılabilir." } \\
\text { (K5) }\end{array}$ \\
\hline Görevli yardımı & "Ben hep görevlilerden yardım istiyorum. Bunun yerine bize bir gö- \\
\hline
\end{tabular}


(2 katılımcı) revli yardımı biz istemeden sağlanabilir." (K6)

Fişlerde kabartma "Mesela fiş alırken kabartma alfabesi olabilir." (K7)

(1 katılımcı)

Kılavuz izi "Nereye gideceğimizi tam olarak bilemediğimizden binalarda kılavuz

(1 katılımc1) izi olmalı." (E4)

\section{Hastaneler Teması}

Görme engelli bireylerin hastanelerde yaşadıkları problemlere yönelik olarak bağımsız hareket, fiziksel koşullar, kabartma sistemi, yazıların büyüklüğü, kalabalık, yaygınlaşma, diğer bireylerin tutumu, kılavuz izi ve uygulanabilirlik olmak üzere temel kategoriler belirlenmiştir. Ayrıca hastanelerde yaşadıkları problemlere yönelik olarak ise görevli yardımı, kabartma sistemi, yazıların büyüklüğü, engelli yolu, bilinçlendirme, yaygınlaşma ve kılavuz izi olmak üzere temel kategoriler oluşturulmuştur.

Tablo 5. Hastaneler temasına ait kategoriler ve örnek görüşler

\begin{tabular}{|c|c|}
\hline \multicolumn{2}{|r|}{ Yaşanılan problemler } \\
\hline Kategori adi & Örnek görüş \\
\hline $\begin{array}{l}\text { Bağımsız hare- } \\
\text { ket } \\
(2 \text { katılımcı) }\end{array}$ & $\begin{array}{l}\text { "Tek başına hastaneye gidemiyorum. Görevli ya da biri olmadığı için } \\
\text { zorluk yaşıyorum. Özellikle evli bireyler sıkıntı yaşıyor. Mesela eşlerden } \\
\text { ikisi de görme engelli ise gerçekten zor. Her zaman yanına biri eşlik } \\
\text { etmiyor." (K8) }\end{array}$ \\
\hline $\begin{array}{l}\text { Fiziksel koşullar } \\
\text { ( } 2 \text { katılımcı) }\end{array}$ & $\begin{array}{l}\text { "Hastanelerin fiziksel şartları bizlere uygun değil. Örneğin koridorda } \\
\text { sandalyeler var. Ama bizde duvar sayma var. Sandalyeler bunu engelli- } \\
\text { yor. Ayrıca sadece kapı girişlerinde ve bazı yerlerde engelli yolu var." } \\
\text { (K5) }\end{array}$ \\
\hline $\begin{array}{l}\text { Kabartma siste- } \\
\text { mi } \\
(1 \text { katılımcl) }\end{array}$ & “Kabartma sistemi olmadığı yerlerde çok zorluk çekiyoruz." (K3) \\
\hline $\begin{array}{l}\text { Yazıların bü- } \\
\text { yüklüğü } \\
(1 \text { katılımcı) }\end{array}$ & $\begin{array}{l}\text { "Ben az görüyorum. Doktorların tabelasındaki yazılar daha büyük } \\
\text { puntolarla olabilir. Levhalar daha büyük olabilir." (K4) }\end{array}$ \\
\hline $\begin{array}{l}\text { Kalabalık } \\
\text { (1 katılımcı) }\end{array}$ & "Çok kalabalık çok sıra bekliyoruz. Bazen öncelik tanıyorlar." (K6) \\
\hline $\begin{array}{l}\text { Yaygınlaşma } \\
\text { (1 katılımcı) }\end{array}$ & $\begin{array}{l}\text { "Gittiğim bazı hastanelerde kılavuz çizgi var, kabartma çizgileri var. } \\
\text { Sağlık Bakanlığının hasta hakları uygulaması var. Buton uygulaması } \\
\text { var. Görevli size yardım ediyor. Ancak bu yaygın değil. Her yerde yok. } \\
\text { Ben belki bazen yararlansam da her görme engelli birey bundan yarar- } \\
\text { lanamıyor." (E3) }\end{array}$ \\
\hline $\begin{array}{l}\text { Diğer bireylerin } \\
\text { tutumu } \\
(2 \text { katılımcı) }\end{array}$ & $\begin{array}{l}\text { "İnsanların tutumları, bazılarının kaba davranışları rahatsız ediyor." } \\
\text { (K7) }\end{array}$ \\
\hline $\begin{array}{l}\text { Kilavuz izi } \\
(1 \text { katılımc1) }\end{array}$ & $\begin{array}{l}\text { Binada kılavuz izi yok. Sıkıntı yaşıyorum kendi başıma hastaneye git- } \\
\text { mem mümkün olmuyor çoğu zaman." (E4) }\end{array}$ \\
\hline
\end{tabular}




\begin{tabular}{|c|c|}
\hline $\begin{array}{l}\text { Uygulanabilirlik } \\
\text { (1 katılımc1) }\end{array}$ & $\begin{array}{l}\text { "Hastanenin girişinde yürüme bandı var. Ama sadece göstermelik } \\
\text { yapılıyor. Görme engelli için hiçbir işe yaramıyor." (E5) }\end{array}$ \\
\hline \multicolumn{2}{|l|}{ Çözüm önerileri } \\
\hline Kategori & Örnek görüş̧ \\
\hline $\begin{array}{l}\text { Görevli yardımı } \\
\text { (7 katılımc1) }\end{array}$ & $\begin{array}{l}\text { "Hastanede bize yardımcı olabilecek bir görevli/refakatçi verilebilir. } \\
\text { Böylece işimizi kendimiz halledebiliriz." (E5) }\end{array}$ \\
\hline $\begin{array}{l}\text { Kabartma siste- } \\
\text { mi } \\
(1 \text { katılımcı) }\end{array}$ & $\begin{array}{l}\text { "Hastanelerde kabartma sistemi olmalı. Çünkü orada daha çok zorluk } \\
\text { çekiyoruz." (K3) }\end{array}$ \\
\hline $\begin{array}{l}\text { Yazıların bü- } \\
\text { yüklüğ̈̈ } \\
(1 \text { katılımcı) }\end{array}$ & $\begin{array}{l}\text { "Doktorların tabelalarındaki yazılar daha büyük harflerle yazılabilir. } \\
\text { Levhalar daha büyük olabilir." (K4) }\end{array}$ \\
\hline $\begin{array}{l}\text { Engelli yolu } \\
\text { (1 katılımc1) }\end{array}$ & $\begin{array}{l}\text { "Engelli yolu bazen sadece hastane girişlerinde oluyor. Ama içerisinde } \\
\text { de her yerde olmalı. Böylelikle bağımsız hareketimizi gerçekleştirebili- } \\
\text { riz." (K5) }\end{array}$ \\
\hline $\begin{array}{l}\text { Bilinçlendirme } \\
\text { (2 katılımcı) }\end{array}$ & $\begin{array}{l}\text { "İnsanları bilinçlendirme noktasında bir şeyler yapılabilir. Çünkü insan- } \\
\text { ların ve görevlilerin tutumlarından rahatsı olabiliyoruz bazen. Bu } \\
\text { yüzden çeşitli iletişim seminerleri uygulanabilir." (E1) }\end{array}$ \\
\hline $\begin{array}{l}\text { Yaygınlaşma } \\
\text { (1 katılımcı) }\end{array}$ & $\begin{array}{l}\text { "Bazı hastanelerde özellikle engelli bireyler için güzel ve yararlı uygu- } \\
\text { lamalar var. Ancak bu her yerde yaygın olsa. Her şehirde her hastanede } \\
\text { olsa. En azından uygulama ve yaygınlaşma noktasında çalışmalar ya- } \\
\text { pılmalı." (E3) }\end{array}$ \\
\hline $\begin{array}{l}\text { Kilavuz izi } \\
\text { (1 katılımc1) }\end{array}$ & "Binada kılavuz izi olması gerekiyor." (E4) \\
\hline
\end{tabular}

\section{Tartışma ve Sonuç}

$\mathrm{Bu}$ araştırmada görme engelli bireylerin toplumda kent yaşamında özellikle toplu ulaşım, park ve bahçeler, ortak kullanım alanları, resmi daireler ve hastanelerde yaşadıkları zorlukların neler olduğu ve problemlerin çözümüne yönelik ne tür önerilerde bulundukları görüşme yöntemi ile ele alınmıştır. Öncesinde alan yazın taranarak görme engelli bireylerin kent yaşamında karşılaştıkları başlıca alanlar belirlenerek bu alanlara yönelik görme engelli bireylerin görüşleri alınmıştır. Araştırmadan elde edilen sonuçlara göre, görme engelli bireylerin toplu ulaşımda en çok yaşadıkları problemler otobüslerde ve duraklardaki sesli sistemin olmamasıdır. Bunun haricinde otobüslerde yer bulma, sistemlerin çalışmaması ve insanların tutumları ile ilgili olarak problemler yaşamaktadırlar. Görme engelli bireylerin çözüm önerileri noktasında otobüs ve duraklara sesli sistem uygulaması öne çıkmaktadır.

Görme engelli bireylerin park ve spor alanlarında en çok yaşadıkları problemler sarı çizgiler, rampa ve tümsekler ile güvenliktir. Yine çözüm önerileri olarak sarı çizgi uygulamalarının arttırılması öne çıkmaktadır. 
Görme engelli bireylerin ortak kullanım alanlarında en sık yaşadıkları problemler temizlik problemidir. Kullanılan tuvaletlerin genellikle temiz olmadığını ve görme engeliyle birlikte çok sıkıntı yaşadıklarını ifade etmişlerdir. Yine özellikle ortak tuvaletlerde Brail uygulaması ve temizliğin sağlanması konusunda önerilerini belirtmişlerdir. Resmi dairelerde en çok yaşanılan problemler ATM'lerin sesli olmaması ve imza konusundadır. Tüm ATM'lere sesli sistemin getirilmesi ise en çok ifade edilen öneridir. Son olarak, araştırmaya katılan görme engelli bireyler hastanelerde bağımsız hareket, binaların fiziksel imkanları, kalabalık ve diğer insanların tutumları konusunda sıklıkla problem yaşarken, en çok hastanelerde kendilerine görevli yardımı almak istemektedirler.

Kentlerde yaşayan bireylerin giderek artması şehir yaşamını daha zor hale getirmektedir. Kentlerin yaşanılabilir olması kentlerde yaşayan tüm paydaşların ortak görevidir (Çakır- Sümer, 2015). Merkezi ve yerel yönetimlerin engelliler için erişilebilirlik hizmetini sağlamaları onların engellilere yönelik en temel sorumluluklarından biridir (Şat ve Göver, 2017). Akıncı ve Sönmez (2015)'e göre çağdaş toplumların önemli göstergelerinden biri engellilerin önündeki engellerin kaldırılmasıdır. Onlara göre engelli ve yakınlarının ihtiyaç ve beklentilerine cevap verilmesi gerekir.

Araştırmada öne çıkan problemlerden biri engellilerin özellikle sağlık hizmetlerinde yaşadıkları sorunlardır. Engelli hizmeti olan sağlık birimlerinde bile özellikle uygulanabilirlik konusunda sıkıntılar yaşanmaktadır. Katılımcılar refakatçi sağlanması konusunda öneri getirmişlerdir. Bodur ve Durduran (2009)'a göre, engelliler özellikle sağlıkla ilgili problemlerinde ikinci planda kalmaktadır ve sağlık hizmetlerinden yararlanması konusu önemli hale gelmektedir. Bunun yanı sıra iç mekan (Pehlivanoğlu, 2012) ve konaklama tesisleri (Şahin ve Erkal, 2012) ile ilgili engelli ihtiyaçlarına cevap verecek sosyal politikalar oluşturulmalıdır. Örneğin, birçok konaklama tesisinin girişi engelliler için uygun değildir. (Şahin ve Erkal, 2012). Ayrıca çalışanların engellilerin ihtiyaç ve beklentileri hakkında bilinçlendirilmesi gerekmektedir (Pehlivanoğlu, 2012) ki bu durum araştırma sonuçları ile benzerlik göstermektedir. Uslu ve Shakouri (2014)'ye göre hassas gruplar için tahsis edilmiş toplumsal alanlar çoğu zaman amacına ulaşamamaktadır. Bu araştırmanın sonuçları da benzer problemlere işaret etmektedir. Katılımcıların birçoğu her ne kadar kent yaşamında engellilere yönelik uygulamaların var oldukların ifade etseler de bu uygulamaların işlevselliği konusunda bazı sıkıntılar yaşandığını dile getirmişlerdir. 
Sonuç olarak, bu araştırmanın bazı sınırlılıkları bulunmaktadır. Araştırma farklı düzeyde görme kaybı yaşayan görme engelli bireylerle sınırlıdır. Ayrıca araştırmada verilerin toplanmasında nitel araştırma yöntemlerinden görüşme tekniğinden yararlanılmıştır. Gelecek farklı engel grubunda bulunan bireylere yönelik farklı değişkenlerin de ele alındığı nitel ya da nicel araştırmalar yürütülebilir. Uygulama konusunda ise kamu spotları ile kentlerde yaşayan bireylere engellilere yönelik tutum ve davranışları konusunda farkındalık kazandırılabilir. Çeşitli seminerler vasıtasıyla insanlar engellilerle iletişim konusunda bilinçlendirilebilir. Çünkü araştırmaya katılan birçok görme engelli birey toplumun konu ile ilgili bilinçsizliğini ifade etmiştir. Özellikle çocukluktan itibaren hem ailede hem de okulda öğretmenler vasıtası ile çocuklara engelli bireylerle iletişim ve tutumlara yönelik bir çok beceri kazandırılabilir. Öğretmen ve yöneticilerin öğrencilerin çeşitli beceri ve tutumları üzerindeki rolünü ortaya koyan farklı araştırmalar mevcuttur (Büyükkaragöz ve Kesici, 1998; Kesici, 2007; 2014; 2015; Izgar, Gürsel, Kesici ve Negiş, 2004). Ayr1ca özel eğitim öğretmenlerinin engelli öğrencilerine yönelik görüşleri ile ilgili yapılmış çalışmalar da konunun önemine vurgu yapmaktadır (Girgin-Büyükbayraktar, Konuk-Er ve Kesici, 2017a; 2017b). Bunun yanı sıra özel eğitim öğretmenlerinin ve öğretmenlerin psikolojik ihtiyaçlarının karşılanması yaşam kaliteleri (Bozgeyikli, 2018) ve stres düzeyleri açısindan (Avcı, Bozgeyikli ve Kesici, 2017) oldukça önemlidir. Ayrıca uygulama ve işlevsellik konusunda belediyeler çeşitli yaptırımlar geliştirerek engellilere yönelik kent alanı ve cihazların kullanılabilirliğini arttırabilir. 


\title{
Extended Abstract
}

\section{Unimpaired City: Problems of Visually Impaired People in City Life}

\author{
Hatice İrem Özteke Kozan Hasan Bozgeyikli \\ Şahin Kesici \\ N. Erbakan University \\ Erciyes University \\ N. Erbakan University
}

Cities that develop rapidly with the technological and industrial changes, started to restructure without a plan and the life is getting difficult in each day for the individuals. Even unimpaired people have difficulties with conurbation in cities; life is not very easy for those who have impairments (Bekci, 2012). Implementations related to furniture, housing or environmental designs lead to a significant decrease in life quality of impaired individuals (Çınar, Arslan, Öztürk and Bülbül, 2015). Impaired people must have the same chance with others witout being alienated (Şat and Göver, 2017). Several studies reveled that both in Turkey (Bekci, 2012; Çınar et al., 2015; Kaplan and Öztürk, 2004; Uslu and Shakouri, 2014) and international literature (Beverley, Bath and Booth, 2004; Bromley, Matthews and Thomas, 2007; Rimmer, Riley, Wang, Rauworth and Jurkowski, 2004) people who have various impairments have some problems in city life.

Among other groups, visually impaired people need more support to maintain their lives independently (Aydin, 2012). It is very important for these individuals to go school or market own by own and to know basic skills for the traffic (Çakmak, 2011). In current study, we aimed to reveal the problems that visually impaired people face in cities regarding public transportation, park and gardens, common use areas, state offices and hospitals. Despite the fact that, some rules and report were created and published regarding city life planning, there exist some problems in practicality. In sum, we aimed to reveal city life problems and solution 
offers of visually impaired people by using qualitative method. So, this current study will bring a unique contribution into the literature.

\section{Method}

Phenomenological approach one of the methods in qualitative studies was used in current study. In qualitative studies, interviews, observations or document analysis are used and perceptions are given in their natural environments (Yıldırım and Şimşek, 2006).

\section{Study Group}

Study group consists of fourteen visually impaired individuals from different cities in Turkey such as Konya, Elazig, Eskisehir and Mersin. Snowball sampling method was used.

\section{Semi Structured Interview Technique}

Semi structured interview technique was used in data collection. In the first phase, creating semi structured interview form- literature was examined then the questions were prepared. For validity of the form, five lecturers from the departments of Special Education and Counseling Psychology examined the questions and based on their suggestions the form was renewed. Then the pilot study was conducted and after the suggestions of pilot study participants the last form was created.

\section{Data Collection}

Individuals in current study voluntarily participated into this work. Moreover, they were informed the privacy of their identity. The data was collected via semi structured interview form and it lasts approximately 20 to 25 minutes.

\section{Data Analysis}

For data analysis content and descriptive analyze techniques were used. Aim of content analysis, is to arrive notions and relations that explain the data. Content analysis is a deeper technique than the descriptive and that provide an insight to a discovery of unnoticeable notions (Yildırım and Şimşek, 2006). The views of participants were collected via semi-structured interview form and answers were coded starting one to fourteen. Problems and solution offers were analyzed by using both descriptive and content analysis. Sample for each category also given in findings.

\section{Results and Discussion}

In current study the problems of visually impaired individuals in cities and their solution offers were examined by using qualitative method. Results of study indicated that visually impaired people have problems in city live such as in the areas of public transportation, parks and gar- 
dens, common use areas, state offices and hospitals. The most common problems for the public transportation are absence of voice systems in buses and bus stops. Moreover, finding a seat, fail to work of systems, of other people's attitudes are general problems of visually impaired peoples. Suggestions for public transportation are in line with problems that they complain about.

For the second theme, visually impaired people complain for yellow lines, ramps and mounds in parks and gardens. For the solutions, they reported that yellow lines may be increase in lots of parks. In third theme, common use areas- visually impaired people have problems in cleaning of toilets. They emphasized that the toilets in common use areas are dirty and they have difficulties for using these toilets. Their solution offers for this theme are using Brail as a gender marker and cleaning the toilets. For the theme of state offices, participants have problems about ATM and signature. They emphasized that not every ATM has a voice system and the working staff of banks want them to sign for the documents. The most common suggestion is bringing a voice system to every atm. Lastly, physical structure of buildings, crowd and others' attitudes are most reported problems for participants in the hospitals. Moreover they generally stated that an officer that the hospital provides for them may help visually impaired people in hospitals.

One of the problems that come to the forefront in current research is health systems. Bodur and Durduran (2009) stated that impaired people generally stay in the background in the health systems and these people must benefit from health services. Besides, social policies need to be done especially in indoor (Pehlivanoğlu, 2012) and pension (Sahin and Erkan, 2012) services toward to needs of impaired individuals. According to Uslu and Shakouri (2014) social areas assign for these groups have problems in obtaining their goals. Results of current study indicated the same problem. Even most of the participants accept the existence the rules and applications for impaired people, they emphasized that problems occur in their functionality.

\section{Kaynakça/References}

Akıncı, Z. ve Sönmez, N. (2015). Engelli bireylerin erişilebilir turizm beklentilerinin değerlendirilmesine yönelik nitel bir araştırma. Anatolia: Turizm Araştırmaları Dergisi, 26(1), 97-113. 
Avcı, A., Bozgeyikli, H. ve Kesici, S. (2017). Psychologicalneeds as thepredictor of teachers' perceivedstresslevels. Journal of Educationand Training Studies, 5(4), 154-164.

Aydın, A. (2012). Görme engelli üniversite öğrencilerinin bilgi erişim sorunları üzerine yapılmış bir araştırma. Bilgi Dünyası, 13(1), 93-116.

Bekci, B. (2012). Fiziksel engelli kullanıcılar için en uygun ulaşım akslarının erişebilirlik açıdan irdelenmesi: Bartın kenti örneği. Bartın Orman Fakültesi Dergisi, 14(21), 26- 36.

Beverley, C. A.,Bath, P. A. ve Booth, A. (2004). Healthinformationneeds of visually impairedpeople: a systematicreview of theliterature. HealthESocialCare in the Community, 12(1), 1-24.

Bodur, S. ve Durduran, Y. (2009). Konya'da engelli çocukların sağlık hizmetlerinden yararlanma ve beklenti durumu. Genel Tip Dergisi, 19(4), 169-175.

Bozgeyikli, H. (2018). Psychological needs as the working-life quality predictor of special education teachers. Universal Journal of Educational Research 6(2), 289-295.

Bromley, R. D., Matthews, D. L. ve Thomas, C. J. (2007). City centre accessibility for wheelchair users: The consumer perspective and the planning implications. Cities, 24(3), 229-241.

Büyükkaragöz, S. S. ve Kesici, Ş. (1998). Eğitimde öğretmenin rolü ve öğretmen tutumlarının öğrenci davranışları üzerindeki etkisi. Milli Eğitim Dergisi, 137, 68-73.

Çakır Sümer, G. (2015). "Engelsiz Şehir" kavramı açısından Malatya. Journal of Management ve Economics, 22(1), 113-138.

Çakmak, S. (2011). Görme engeli olan bireyler için hazırlanan otobüse binme becerisi öğretim materyalinin etkililiği. Hacettepe Üniversitesi Eğitim Fakültesi Dergisi, 41(41), 94-111.

Çınar, H., Arslan, A. R., Öztürk, A. M. ve Bülbül, R. (2015). Kamu binaları: Engellilerin donatı ve mobilya kullanımına yönelik yaşam analizi. Mühendislik Bilimleri ve Tasarm Dergisi, 3(3), 329-337.

Girgin-Büyükbayraktar, Ç.,Konuk-Er, R. ve Kesici, S. (2017a). According to the opinions of teachers of individuals with intellectual disabilities: What are the sexual problems of students with special education needs? How should sexual education be provided for them?. Journal of Education and Practice, 8(7), 107-115.

Girgin-Büyükbayraktar, Ç.,Konuk Er, R. ve Kesici, S. (2017b). Creating awareness of sexual abuse in children with special education needs: Depending on the opinions of teachers of the mentally handicapped. Journal of Education and Training Studies, 6(1), 151-158.

Izgar, H., Gürsel, M., Kesici, Ş. ve Negiş, A. (2004). Önder davranışlarının problem çözme becerisine etkisi. XIII. Ulusal Eğitim Bilimleri Kurultayı, 6-9.

Kaplan, H. ve Öztürk, M. (2004). Engelliler, Kamu mekanı ve engelsiz tasarım: Kamusal iç mekanlarda irdelenmesi için bir çerçeve. Planlama Dergisi, 2, 67-74.

Kaplan, H. ve Ulvi, H. Engellilerin kaldırım ve yaya geçitlerinde karşılaştıkları kaza riskleri: Konya kent merkezi örneklemi. Öz-Veri, 6(2), 1483-1512. 
Kesici, Ş. (2007). Şube rehber öğretmenlerinin görüşlerine göre 6. 7. ve 8.sınıf öğrencilerinin rehberlik ve danışma ihtiyaçları. Selçuk Üniversitesi Sosyal Bilimler Enstitüsü Dergisi, 17, 365-383.

Kesici, S. (2014). Human values as predictors of motivationalbeliefs in highschoolstudents.Anthropologist, 18(3), 869-875.

Kesici, S. (2015). Psychological needs as predictors of human values in high school students. The Anthropologist, 19(2), 499-506.

Pehlivanoğlu, B. (2012). Konaklama yapılarının engellilere yönelik oda düzenlemelerinin irdelenmesi. İnönü Üniversitesi Sanat ve Tasarnm Dergisi, 2(4), 27-35.

Pirgon, Y. ve Babacan, E. (2013). Görme engelli öğrencilerin piyano eğitimi üzerine durum çalışması. Selçuk Üniversitesi Sosyal Bilimler Enstitüsü Dergisi, (29), 191-206.

Rimmer, J. H., Riley, B., Wang, E., Rauworth, A. veJurkowski, J. (2004). Physical activity participation among persons with disabilities: barriers and facilitators. American Journal of Preventive Medicine, 26(5), 419-425.

Şahin, H. ve Erkal, S. (2012). Ortopedik ve görme engelli bireyler için konaklama tesislerinde yapılması gereken düzenlemeler. Hacettepe Üniversitesi Sosyolojik Araştırmalar Dergisi, 1-13.

Şat, N. ve Göver, T. (2017). Engelliler için belediyelerin erişilebilirlik sorumlulukları: Çorum engel haritası projesi. Hitit Üniversitesi Sosyal Bilimler Enstitüsü Dergisi, 10(1), 521- 542.

Uslu, A. ve Shakouri, N. (2014). Kentsel peyzajda engelli/yaşlı birey için bağımsız hareket olanağı ve evrensel tasarım kavramı. Kastamonu Üniversitesi Orman Fakültesi Dergisi, 14(1), 7-14.

Yıldırım, A. ve Şimşek, H. (2006). Sosyal bilimlerde nitel araştırma yöntemleri. Ankara: Seçkin Yayınevi.

Yılmaz, F. ve Çakırer Özservet, Y. (2013). Yerelden Engelsiz Tasarım Uygulamaları, Küçükçekmece Belediyesi Örneği, I. Ulusal "Engellileştirilenler" Sempozyumu, 7-8 Kasım 2013, Ulaşılabilir Kentler Engelsiz Mekânlar (UKEM) Hareketi, Selçuk Üniversitesi Mimarlık Bölümü, Konya, Kongre Kitabı s.150-160.

\section{Yrd. Doç. Dr. Hatice İrem Özteke Kozan}

Selçuk Üniversitesi Rehberlik ve Psikolojik Danışmanlık alanında Lisans ve Yüksek lisans, Necmettin Erbakan Üniversitesi Rehberlik ve Psikolojik Danışmanlık alanında doktora derecelerine sahiptir. Yüksek Lisans ve doktora öğrenimi süresince araştırma görevliliği yapan yazarın yurt içi ve yurt dışı çeşitli yayınları ve kitap çevirileri bulunmaktadır. Doktora sürecinde tez ile ilgili araştırmalarını Amerika Birleşik Devletlerinin Kansas eyaletinde gerçekleştirmiştir. Halen Necmettin Erbakan Üniversitesi Rehberlik ve Psikolojik Danışmanlık Anabilim dalında öğretim üyesi olarak görev yapmakta, lisans ve yüksek lisans düzeyinde ders vermektedir. Başlıca çalışma alanları, yakın ilişkiler, yetişkinlerde Bağlanma, sosyal medya ve internet kullanımıdır.

Dr. Ozteke Kozan has a bachelor's and master's degree in Counseling Psychology at Selcuk University. She got her doctoral degree in the same department -Counseling Psychology- 
at Necmettin Erbakan University. During her master's and doctoral process, she worked as a research assistant and she has national and international articles in addition to books translations. During the doctoral process, she worked as a research follow in the University of Kansas - U.S.A.-. Dr. Kozan is still working as a faculty member in Necmettin Erbakan University and conducting master and bachelor's lessons. Most commonly, she studies Attachment Theory, social media and close relationships.

E-mail: iromozt_1907@hotmail.com

\section{Doç. Dr. Hasan Bozgeyikli}

Selçuk Üniversitesi Rehberlik ve Psikolojik Danışmanlık alanında lisans mezunu olan Bozgeyikli, yüksek lisans ve doktora öğrenimini yine aynı üniversitede Eğitimde Psikolojik Hizmetler alanında tamamlamıştır. Yurt içi ve yurt dışında yayınlanmış bir çok makalesi bulunan yazarın kitapları ve kitap bölümleri de alana kazandırılmıştır. Çeşitli idari görevlerde bulunan Bozgeyikli, halen Erciyes Üniversitesi Eğitim Fakültesi, Rehberlik ve Psikolojik Danışma Anabilim dalında öğretim üyesi olarak görev yapmaktadır.

Dr. Bozgeyikli graduated from Counseling Psychology at Selcuk University and he completed master's and doctoral degrees at the same university. He has several natinal and international articles, books and book chapters. He conducted several administirative tasks and he is still working as a faculty member in Erciyes University at the department of Counseling Psychology.

E-mail: hbozgeyikli@gmail.com

\section{Prof. Dr. Şahin Kesici}

Selçuk Üniversitesi Rehberlik ve Psikolojik Danışmanlık alanında lisans mezunu olan Kesici, yüksek lisans ve doktora öğrenimini yine ayn üniversitede Eğitimde Psikolojik Hizmetler alanında tamamlamıştır. Lisansüstü eğitimi boyunca araştırma görevliliği ve öğretim görevliliği yapmış olan yazarın alanda yazılmış birçok kitabı, ulusal ve uluslararası makalesi bulunmaktadır. Halen Necmettin Erbakan Üniversitesi Rehberlik ve Psikolojik Danışmanlık anabilim dalında öğretim üyesi olarak görev yapmaktadır.

Dr. Kesici graduated from Counseling Psychology-Selcuk University-. He also completed his master's and doctoral degrees at the same university. During graduate studies, he worked as a faculty member and he has several national and international articles, books and book chapters. He is still working as a faculty member in Necmettin Erbakan University, at the department of Counseling Psychology.

E-mail: sahinkesici@konya.edu.tr

\section{Kaynakça Bilgisi / Citation Information}

Özteke Kozan, H. İ., Bozgeyikli, H., Kesici, Ş. (2018). Engelsiz kent: Görme engelli bireylerin kentlerde yaşadıkları problemler. IDEALKENT - Kent Araştırmaları Dergisi, 23, 216-235. 